\title{
Filosofia e Educação: as mediações da política cultural
}

Resumo: O presente artigo parte da resistência demonstrada pelos estudantes de graduação ao estudo de conceitos abstratos e sua preferência por narrativas. Relaciona essa situação às dificuldades de compreensão recíproca entre intelectuais (os "de cima”) e povo (os "de baixo", os "pobres"), as quais não se referem apenas à linguagem, mas também aos conceitos filosóficos. Conclui, afirmando a necessidade de incentivar os jovens, desde o Ensino Médio, à especulação filosófica, salientando a importância de que aqueles que se dedicam à atividade científica assumam também suas responsabilidades políticas, reconhecendo a educação e a cultura como campos de batalha nos quais se formam núcleos dinâmicos de combate que, sem deixar de ser particulares, envolvem o destino coletivo do país.

Palavras-chave: tempo; realidade; subjetividade.

Philosophy and education: mediations of cultural politics

Abstract: This article is about university students' resistance to studying abstract concepts and their preference for narratives. The author establishes a relationship between this situation and the difficulties in reciprocal understanding between intellectuals (the "upper-class" ones) and the people (the "lower-class" ones, or the "poor" ones). These difficulties are not only related to language, but also to philosophical concepts. He concludes his ideas by stating that it is necessary to encourage youngsters, from high school, towards philosophical speculation and that it's very important for those who dedicate to scientific activity to also take their political responsibilities, recognizing education and culture as battlefields on which dynamic battle centers are formed, involvoing the collective future of a country, without losing particularity.

Key words: time; reality; subjectivity.

Começo a abordar meu tema - as dificuldades e as possibilidades do ensino de filosofia da educação - e, desde estas linhas iniciais, disponho-me a atender a uma demanda frequente entre os estudantes. Nossos alunos gostam de experiências vividas.

* Professor do Departamento de Educação do Centro de Teologia e Ciências Humanas da Pontifícia Universidade Católica do Rio de Janeiro (PUC-Rio), RJ, Brasil. leokonder@terra.com.br 
Ao longo de mais de um quarto de século, percebi que muitos jovens se sentiam indecisos, inseguros, quando lhes apareciam conceitos teóricos muito abstratos, como são os conceitos filosóficos. Quando eram evocados episódios ou narrados acontecimentos (talvez até com uma ponta de pitoresco), havia como uma reanimação na sala.

Enfrentando a resistência que se manifestava entre os alunos contra o que chamavam abstrato, recorri a Hegel, o filósofo alemão, que distinguia entre o concreto e o abstrato em termos que me pareciam interessantíssimos: se me limito a usar minha caneta, pouca coisa aprenderei sobre ela e só terei dela um conhecimento abstrato. Para conhecer concretamente a caneta, sua história, sua função, a paciente invenção da sua estrutura, é preciso compreendê-la no seu movimento, no seu intercâmbio com o meio ambiente e no projeto do seu possuidor. E Hegel, provocativamente, dizia que a consciência dos sujeitos precisa crescer com o seu conteúdo ("concreto" vem de "crescido"+ "com").

Pois bem, embora a ideia fosse boa e o professor estivesse encantado com ela, só consegui interessar quatro alunos pelo pensamento de Hegel, num percurso de mais de quarenta turmas. Praticamente, nas turmas de graduação, essa discussão esteve sempre presente, e eu tive sempre a impressão de que precisamos levá-la às aulas de filosofia no Ensino Médio. Por um momento, na historinha que contei, veio-me à cabeça a hipótese de que os alunos da graduação se ressentiam de um certo atraso na assimilação de uma matéria que lhes faltara na passagem pelo Ensino Médio.

II

É preciso formar um esboço de estruturação do pensamento filosófico já no Ensino Médio.

Sem precipitação, mas com alguma firmeza, para que as ideias, depois, sejam articuladas de maneira a pensar criticamente a relação entre a reflexão já constituída e as novas ideias.

Nesse processo, os de baixo têm sentimentos contraditórios: admiram obras que nem sempre entendem. A erudição alcançada por muitos intelectuais e artistas, cientistas e políticos tradicionais merece respeito. Porém eles pagam um preço alto por se fixarem, consciente ou inconscientemente, nos horizontes da classe dominante, subestimando a criatividade da classe dominada. Mas a experiência histórica desmentiu o que poderíamos chamar de subestimação aristocrática dos de cima, quando insistem em ignorar as potencialidades dos pobres, que podem ser surpreendentemente criativos. E comprovou historicamente que nos poucos momentos em que se abriu para o aproveitamento cultural das criações das camadas populares surgiram obras de arte extraordinari- 
amente significativas, como, por exemplo, na França e na Itália do Renascimento. Os leitores do padre François Rabelais nunca hão de esquecer as histórias da família de gigantes que ele recriou literariamente.

No Brasil, as coisas têm caminhado devagar. Quando as mudanças se tornam imperativamente necessárias, elas vão se fazendo, mas tudo em ritmo lento. Entre os intelectuais ainda se encontram manifestações de desinteresse e desprezo pelos pontos fortes da cultura popular. Mesmo democratas descuidam-se e deixam transparecer preconceitos em relação à cultura dos outros.

Os de cima são desafiados a levar em conta a dificuldade que os de baixo têm para entendê-los, porém deveriam prestar atenção também nas suas próprias dificuldades para entender o que se passa na dimensão ideológica da consciência deles. Se formos forçados a simplificar, diremos: os ricos sofrem distorçōes no pensamento, que eles mesmos custam muito a reconhecer.

Até certo ponto é bom que os homens acreditem nos valores da cultura particular em que foram criados. É saudável que tenham valores e convicções. O perigo está em exagerar nas suas crenças e esquivar-se ao diálogo com os outros. Não é raro perceber entre os membros das camadas mais pobres da população certa dificuldade para compreender a linguagem dos ricos.

Mesmo quando se trata de ricos progressistas, os pobres têm uma sensação de estranheza ao ouvi-los criticar o povo e fazer sugestōes para a ação política das camadas populares. Essa dificuldade não é apenas uma dificuldade de linguagem, é uma dificuldade diante do que é filosofia.

III

Se não, vejamos. Na vida quotidiana, em função dos compromissos familiares e do controle do trabalho e dos estudos, estamos sempre marcando as horas, organizando nossos movimentos de acordo com o relógio.

O tempo, medido, aparentemente domesticado, fica um tanto esquecido, subordinado aos nossos projetos. No entanto, conforme já nos advertia Santo Agostinho, estamos sendo vítimas de uma ilusão. Há mais de mil e quinhentos anos cultivamos a convicção de que as nossas limitações temporais não nos impedem de medir o tempo. Com base em que código humano, falível, insistimos em medir aquilo que nos mede, aquilo que é capaz de medir a nossa existência?

$\mathrm{Na}$ passagem da imagem do tempo tal como ela atravessa o nosso dia a dia, igual aos outros seres humanos, podemos nos acostumar a não fazer perguntas. Como também podemos nos adaptar a quaisquer circunstâncias com disposição oportunista óbvia.

Damo-nos conta de que fomos colocados diante de uma questão espinhosa: a do sentido da vida. O conceito de tempo representa experiências distintas 
quando aparece na perspectiva de uns ou transparece na perspectiva de outros e incomoda (democraticamente?) todo o mundo.

Quando um intelectual de esquerda, subjetivamente disposto a dialogar com o povo, fala em tempo histórico, ele manifesta certa impaciência ética, que os trabalhadores não têm espaço para cultivar em suas usuais condições de vida.

Quando os trabalhadores falam em paciência, eles não estão necessariamente capitulando diante da resignação. $\mathrm{O}$ tempo que lhes é imposto exige deles uma capacidade de suportar a pressão, reagindo da forma que lhes parece possível.

O poeta alemão Bertolt Brecht compreendeu esse fenômeno com clareza. É o que se nota numa das pequenas estórias de seu livrinho Estórias de calendário. Uma delas tem como personagem o senhor Keuner. O senhor Keuner estava tranquilamente em sua casa quando ela foi invadida por um gigante fardado que o interpelou: "Queres servir-me?".

O senhor Keuner, então, foi para a cozinha e passou a preparar comida para o invasor. Durante semanas, meses e até anos, preparou acepipes variados, sobremesas deliciosas e excelentes bebidas para o gigante. Um dia, este morreu. O senhor Keuner arrastou o cadáver até o fundo do jardim, jogou-o num buraco e respondeu: "Não!" (Brecht, 1973).

N

Nas condições em que o tempo está presente na experiência e no pensamento do Sr. Keuner, a própria ideia de tempo sofre modificações que não são recusadas (já que são impostas pela realidade), mas são um artifício para parecerem próximas da aceitação da truculência e iludirem o opressor.

Desde que li essa estória, pensei muito na opção do senhor Keuner, pensei nos anos de vida que o gigante (o capitalismo?) acabara roubando dele. Foram anos perdidos, com certeza.

Mas foram também os anos em que a competência do gastrônomo preparou e executou a morte de seu opressor.

Vários processos cruzavam-se no sórdido ambiente da extrema solidão na estorinha do senhor Keuner. Duas correntes estavam constituídas e cada uma representada por um personagem em condições de uma desigualdade escandalosa.

David, na Bíblia, enfrentou e venceu o gigante Golias, mas teve vasto apoio da plateia.

No caso do combate do senhor Keuner, o desequilíbrio de forças era tão grande que obrigou o novo Davi a levar anos pondo em prática sua estratégia. 
Após a invasão da sua casa pelo gigante, suponho que ele se tenha dito: "Excluído qualquer combate, preciso de muita habilidade. Vi que ele gostou da minha comida. Pois bem: como cozinheiro vou me superar em cada prato. Sou o comandante preso de uma fortaleza cercada. Os pratos - obras-primas da arte culinária - são as mediações gastronômicas".

O pequeno texto de Brecht desencadeou discussóes bastante animadas. Cheguei a entusiasmar-me com a vivacidade dos debates em algumas turmas, na realidade, poucas.

Trouxe outros poemas e outros textos pequenos em prosa para a sala de aula. Mas nenhum teve efeito comparável. Emocionavam-se com determinados textos, mas não se dispunham a debatê-los. Por quê? Gostaria muito de receber hipóteses para esse fenômeno.

Desconfio de que o pequeno texto de Brecht reuniu aos olhos dos estudantes a qualidade artística, a densidade de linguagem, mas também o sentido da opção ética de revolta contra a covardia; e uma confusa, mas generosa, solidariedade política.

\section{IV}

Aceito sugestōes para pensarmos juntos, professores e estudantes, qual terá sido a origem da emoção com que muitos alunos reagiram à estorinha do senhor Keuner. Tenho uma hipótese, mas devo reconhecer que ela não exclui diversas dúvidas. Acho que, na reação dos estudantes, em 1984, refletiu-se não só a descoberta de um autor importante cuja obra repercutia neles com força, mesmo que não os arrebatasse.

A época influía nos sentimentos dos jovens, expondo-os a desafios políticos múltiplos. A ditadura militar, na era Geisel, estava promovendo o que ela chamava de distensão lenta, segura e gradual. Geisel foi sucedido por Figueiredo e desencadeou-se no país uma expressiva campanha pelas diretas já. Figueiredo permitiu a mobilização, mas tratou de assegurar as eleições indiretas.

Os melhores comentários, na ocasião, foram feitos pelos humoristas. Luiz Fernando Veríssimo, registrando a prepotência dos discursos da direita e aludindo às condições de isolamento em que ela estava, falou numa "minoria esmagadora".

Tancredo Neves, eleito contra a tal minoria, morreu antes de tomar posse e foi sucedido por Sarney.

Outro humorista - Millor Fernandes -, comentando a cara do então presidente Sarney, na qual transpareciam as marcas das suas ambiguidades, escreveu: "olhando a cara do novo presidente, tenho a impressão de que fomos bigodeados." 
As circunstâncias em que a estorinha de Brecht foi levada aos alunos da PUC e da UFF estavam ligadas a um momento histórico em que o eco das apreensões, dos medos e das angústias estava bastante próximo, porém fortaleciam-se as possibilidades de ação política e o incentivo ético a uma revolta que os jovens associavam a Brecht e ao senhor Keuner.

A combinação de sentimentos complementares e interdependentes, ligados à rebeldia e à prudência, repercutia em favor do primeiro polo, sem, contudo, eliminar o segundo.

Hoje, transcorridos 25 anos, percebe-se que o entusiasmo, a combatividade, a disposição de luta não desapareceram, mas arrefeceram significativamente. Tudo indica que estamos numa nova fase. A sociedade burguesa, entre nós, tem obtido alguns êxitos inegáveis; no entanto, as contradições agravaram-se. Filosoficamente, situações como essa oferecem possibilidades à filosofia, que tem vasta experiência na arte de fazer balanços problematizadores de aspectos complicadores na reflexão sobre a condição humana. O filósofo francês Voltaire já admitia que a filosofia não serve para fazer bons negócios e sim para suportar os prejuízos.

É preciso incentivar desde cedo (o que no nosso caso significa desde o Ensino Médio) a especulação filosófica.

Sabemos que não basta falar, discutir, questionar. Temos consciência de que, para nos libertarmos dos aspectos mais inaceitáveis de uma sociedade tão desigual como a nossa, precisamos agir. O filósofo alemão Lessing já dizia que não basta conquistar o direito de denunciar o uso de algemas, mas é necessário eliminá-las praticamente da realidade (Lessing, 1946).

Lessing ajuda-nos a não esquecer os princípios éticos que nos levam a nos dedicarmos à atividade científica e também a assumir (cada um por seu caminho) nossas responsabilidades políticas.

A educação e a cultura são não só elementos essenciais da nossa identidade nacional, mas são também campos de batalha onde, surpreendentemente, formam-se núcleos dinâmicos de combates que, sem deixar de ser particulares, envolvem o destino coletivo do país.

\section{Referências bibliográficas}

AGOSTINHO, Santo. Confissöes. São Paulo: Nova Cultural, 2004. (Série Os pensadores).

BRECHT, Bertolt. Kalendergeschichten. Frankfurt: Suhrkamp,1973.

LESSING, Gotthold. L'education du genre humain. Paris: Aubier: Editions Montaignes, 1946. 